\title{
NUMERICAL STUDY OF THE MORPHODYNAMIC CHANGE OF INTERTIDAL FLATS DUE TO TIDAL AND COASTAL CURRENTS
}

\author{
Ken-ichi Uzaki ${ }^{1}$, Yoshiaki Kuriyama² and Hikari Sakamoto ${ }^{3}$
}

\begin{abstract}
Numerical model of the morphodynamic change of intertidal flats is very important to maintain intertidal flats and construct artificial flats. In this study, three-dimensional morphodynamic model considering tidal and coastal currents, sand and cohesive sediments was developed and applied to the Shirakawa intertidal flat in the Ariake Sea in Japan. From comparisons between numerical and observation results around the rivermouth of Shirakawa River, we could recognize the qualitative validity of the numerical model. Furthermore, the simultaneous simulation of tidal and coastal currents and the importance of mud content on the calculation of morphodynamic change of intertidal flats were shown.
\end{abstract}

Keywords: morphodynamic change; tidal currents; coastal currents; sand; cohesive sediments; mud content

\section{INTRODUCTION}

Intertidal flats play an important role on the keeping of water quality of the inner gulf, so that many artificial intertidal flats are constructed in these days. In order to maintain these flats by keeping the dynamic equilibrium of sediment budgets, it is very important to establish the forecasting technique of sediment transports and morphodynamic changes of intertidal flats. Numerical simulations are very useful forecasting technique. 3D model is needed to calculate the bottom shear stress accurately and the moving boundary scheme is also needed to calculate the current field on the intertidal flat. Uchiyama (2004, 2005) develop a 3D cohesive sediment transport model due to tidal currents, which is named "WD-POM". It is based on the Princeton Ocean Model, the wetting and drying (WD) scheme and cohesive sediment transport model based on the advection diffusion equation.

Uzaki et al. (2007) applied WD-POM to an intertidal flat at the mouth of the Shirakawa River in the Ariake Sea in Japan. However, the sediment transport of sand should be taken into account. That's because the mud content of intertidal flats, which is the ratio of mud to sand in the bottom soil, takes a wide range from sandy flat to muddy one. In the Shirakawa intertidal flat, muddy soil is located in the offshore of the Kumamoto port and sandy soil around the rivermouth, so that it is needed to use the accurate distribution of mud content in order to forecast the morphodynamic change accurately. Furthermore, coastal currents due to wind waves are also needed to be taken into account because they are one of predominant currents under the storm condition especially at the high tide even on the intertidal flat. Therefore, WD-POM was improved to take sand transports and coastal currents into account and applied to the Shirakawa intertidal flat in order to verify the improved model.

\section{NUMERICAL MODEL}

"WD-POM" is based on the Princeton Ocean Model, the wetting and drying (WD) scheme and cohesive sediment transport model by using the advection diffusion equation. Details of this basement model are described in Uchiyama (2004, 2005). This model is improved to consider sand transport and coastal currents. The wave field is calculated by using the energy balance equation. The surface shear stress due to wave breaking, which is proposed by Newberger and Allen (2007), is calculated by using the wave energy dissipation. The radiation stress, which is proposed by Longuett-Higgins and Stewart (1962) is also calculated in order to express coastal currents. As the sediment transport model of sand, the Bailard model was used because the mean flow and the oscillatory flow due to waves could be considered and the suspended load and the bed load could be also considered simultaneously. However, in this study, the oscillatory flow could not be calculated as Kato et al (2004). The ratio of cohesive sediment transport and sand transport was decided by using the distribution of observed mud content obtained by Nakagawa (2003). Furthermore, the improvement of boundary condition of turbulent

\footnotetext{
${ }^{1}$ Department of Civil and Environmental Engineering, Gunma University, Tenjin-cho 1-5-1, Kiryu City, Gunma Prefecture, 376-8515, Japan

${ }^{2}$ Marine Environment and Engineering Development, Port and Airport Research Institute, Nagase 3-1-1, Yokosuka City, Kanagawa Prefecture, 239-0826, Japan

${ }^{3}$ Engineering Division, Praia Consultant Co. Ltd., Hisamoto 3-3-15, Takatsu-ku, Kawasaki City, Kanagawa Prefecture, 213-0011, Japan
} 
energy equation was also done according to Newberger and Allen (2007a, b) and the feedback of morphodynamic change to wave field were also done.

\section{OUTLINE OF FIELD OBSERVATION}

Topographic surveys and wave observations have been conducted from 1976 to 2003 by Kuriyama et al (2004). Figure.1 shows the survey area and the position of observation site. The survey area spreads $3.5 \mathrm{~km}$ in the longshore direction and $4.0 \mathrm{~km}$ in the offshore one as shown by the rectangular box in the lower figure. Figure.2 (a) indicates the view of the Shirakawa flat, (b) the condition of bottom sediments and (c) waves on the flat at the high tide, respectively. From figure (b), we can see sandy sediments near the rivermouth. From figure (c), we can seed the generation of wind waves at the high tide and it suggests the existence of coastal currents due to wind waves even on the intertidal flat. Figure.3 (a) and (b) show horizontal distributions of topographic change. Figure (a) indicates the topographic change from Oct.1978-Aug.1997 with the large river discharge and (b) from Aug. 1997-Aug. 2002 with no large discharge. From figure (a), with the large river discharge, the large accumulation can be seen in the offshore of rivermouth. On the other hand, from figure (b), slight erosion can be seen around the rivermouth. It suggests that one of important parameters of morphodynamic change is the sediment discharge from rivermouth. Figure.3 indicates the morphodynamic change at the mouth of the Shirakawa River from 2000 to 2002 by using the data of topographic survey. From this figure, we can see the accumulation near the top of Kumamoto Port and the spatially periodic accumulation and erosion along the water route from the rivermouth. Furthermore, at the northside of the water route, a slight accumulation can be also recognized. Kuriyama et al. (2004) also estimate sediment budgets on the intertidal flat by using longshore sediment transport formula. The comparison, however, between numerical and observation results with regard to sediment budgets will be made in the future work.

\section{NUMERICAL SIMULATIONS}

Figure.4 (a) - (c) show the location of the Ariake Sea and numerical domains. Numerical simulations were conducted by using the nesting method. Figure (b) indicates the numerical domain of S1 for the whole Ariake Sea and (c) the domain of S2 for the Shirakawa intertidal flat applying the numerical results of S1 to the boundary condition. In figure (c), the arrow indicates the mouth of Shirakawa river and the rectangular box the survey area by Kuriyama et al. (2004). Table 1 and 2 show numerical conditions. Because of the calculation of intertidal flat, the shoreline moves one or two kilometers, so that the spatial resolution is not coarse to represent the surfzone. 9 simulations were conducted from Run 1 to 9 . Run 1 and 2 were simultaneous simulations of tidal and coastal currents by using cohesive sediment and sand transports. Run 1 was for the storm condition and Run 2 for the calm condition. Run 3 was the simulation of tidal currents. Run 4 and 5 were simulations of coastal currents. Run 4 was for the storm condition and Run 5 for the calm condition. Run 6 and 7 were simultaneous simulations of sand transport only. Run 8 and 9 were simultaneous simulations of cohesive sediment transport only. The calculation period was set at 15 days from Oct.26 to Nov.10 in 2001. From numerical results of 15 days, total morphodynamic changes were calculated by setting storm days at 23 days/year obtained by the NOWPHAS data at the Kumamoto Port. The NOWPHAS means the wave data sampling network in Japan. Wave parameters were set by analyzing the wave data at the Kumamoto Port. The wave height was set at $1.5 \mathrm{~m}$, the wave period at $6.0 \mathrm{~s}$ and wave angle at $45 \mathrm{deg}$. at the offshore open boundary. Coefficients of the Bailard model was set at $\varepsilon_{S}=0.02$ and $\varepsilon_{B}=0.10$ according to Kato et al. (2004). The diameter of sand was set at $0.25 \mathrm{~mm}$, the density of sand at 2.65 $\mathrm{g} / \mathrm{cm}^{3}$ and the density of cohesive sediments at $1.20 \mathrm{~g} / \mathrm{cm}^{3}$. Figure.5 shows the distribution of mud content obtained by Nakagawa (2003). From this figure, muddy sediments are located at the offshore of the port and sandy sediments around the rivermouth.

\section{NUMERICAL RESULTS}

Figure.6 (a) and (b) show horizontal currents at (a) flood tide and (b) ebb tide. In figure captures, $\eta$ indicates tidal elevations. From figure (a), onshore currents can be seen from the deep area. From figure (b), offshore currents can be seen to the deep area and the north end of offshore open boundary. From these figures, complex current fields were made around the rivermouth especially at the flood tide. 


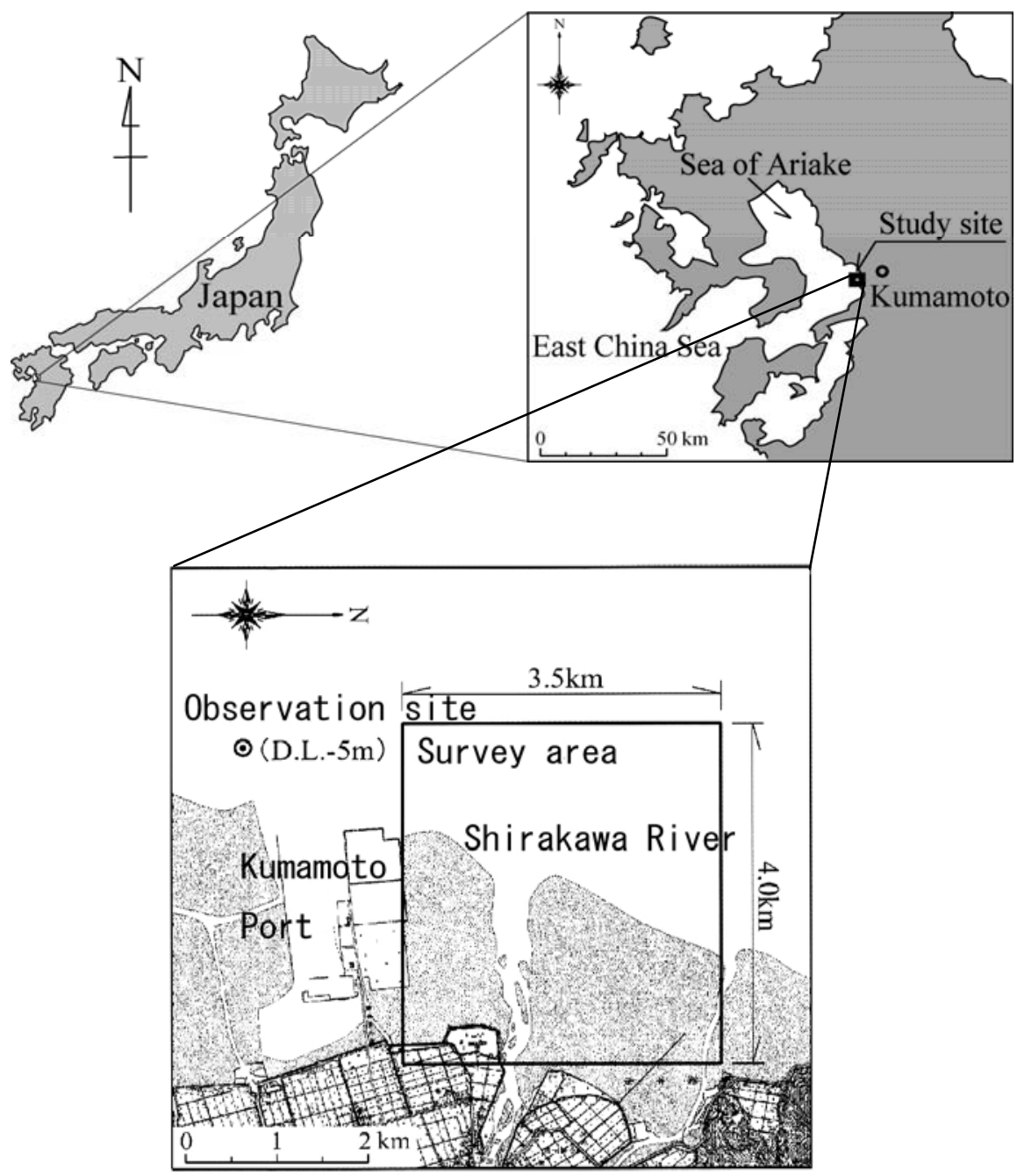

Figure 1. Location of the Shirakawa intertidal flat and the area of field survey.

\section{Qualitative reproduction of morphodynamic change}

Figure.7 (a) and (b) show (a) observation and (b) numerical results of morphodynamic changes around the rivermouth. Figure (b) indicates numerical results of Run 1 and 2. Bottom sediments move well especially in this area. Although the comparison of both figures gives us the difficulty of smallscale reproduction, we can recognize five similar points. The first is the spatially periodic topography along the water route from the rivermouth. The second is the accumulation at the north side of the water route. The third is the accumulation near the top of the Kumamoto Port. The fourth is the total erosion over the whole area. The fifth is the order of accumulation and erosion, (a) \pm 1.20 and (b) \pm 1.45 . From this comparison, it was confirmed that this numerical model could reproduce observation results qualitatively.

\section{Importance of simultaneous simulation of tidal and coastal currents}

Figure.8 (a) and (b) shows numerical results of Run 2, 3, 5 and Run 2, 3, 4, respectively. Figure (a) shows the linear addition of the results of tidal currents only and (b) the results of coastal currents only. Figures (a) and (b) does not agree with observation results with regard to qualitative features and the order of morphodynamic change $\pm 0.865 \mathrm{~m}$. It shows that the linear addition cannot reproduct the observation results and the qualitative agreement between Figure.7 (a) and (b) the importance of simultaneous calculation of tidal and coastal currents. 


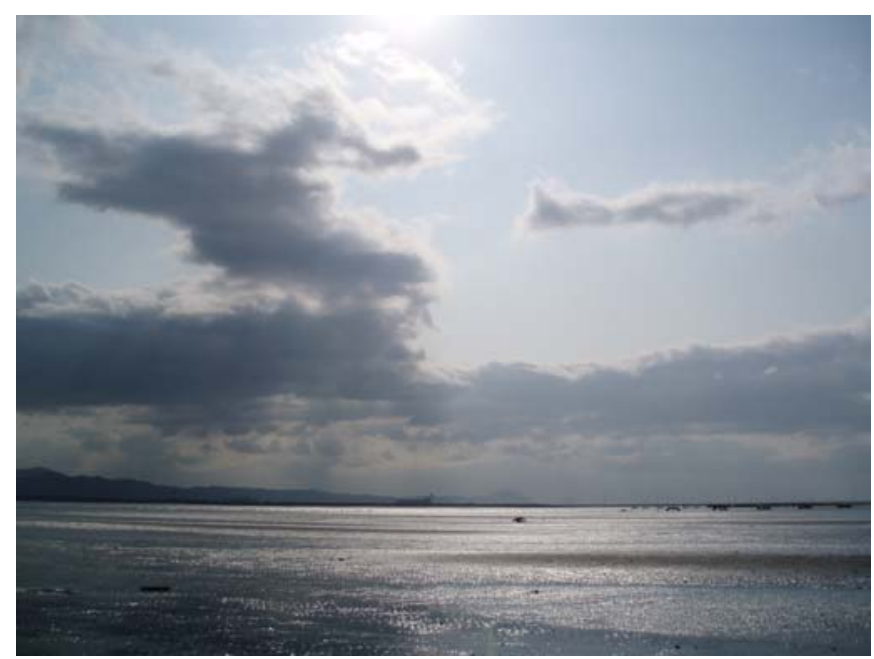

(a) View of the Shirawaka flat.

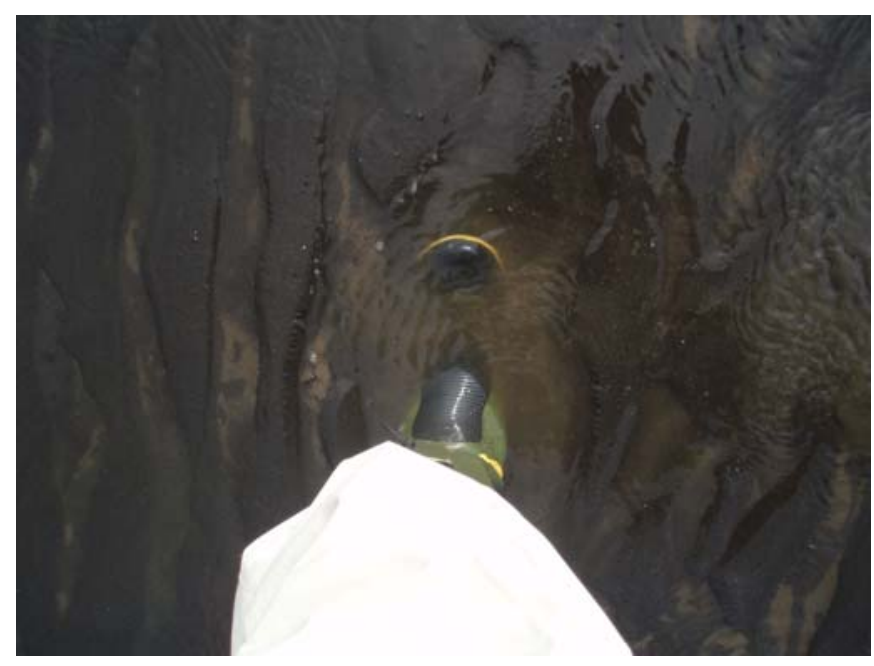

(b) Bottom condition of the Shirakawa flat.

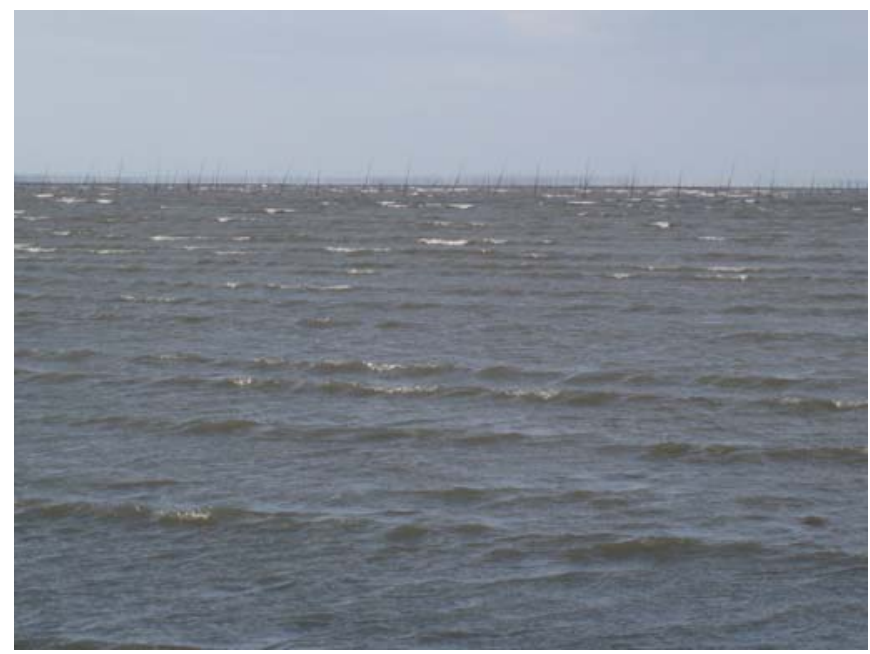

(c) Waves on the Shirakawa flat at the high tide.

Figure 2. Photographs of the Shirakawa intertidal flat. 

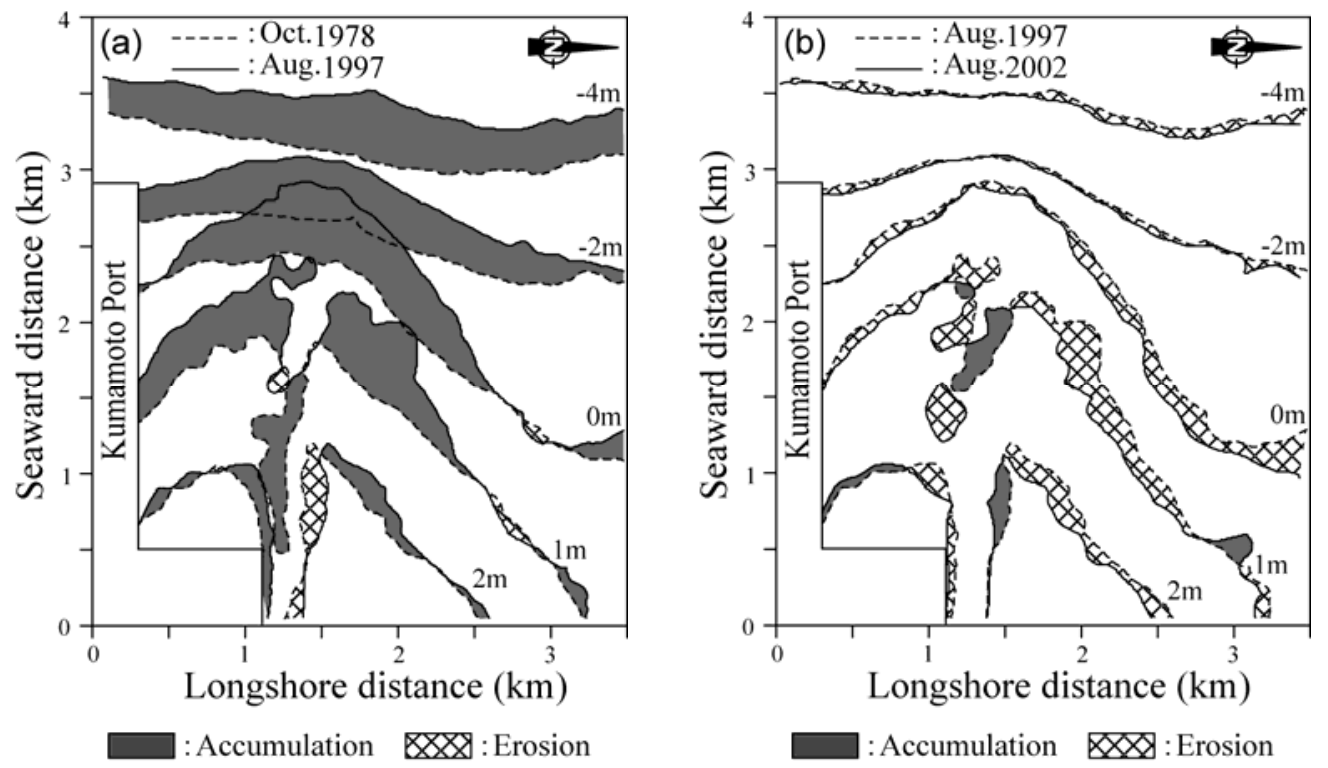

Figure 3. Morphodynamic change of the Shirakawa intertidal flat.

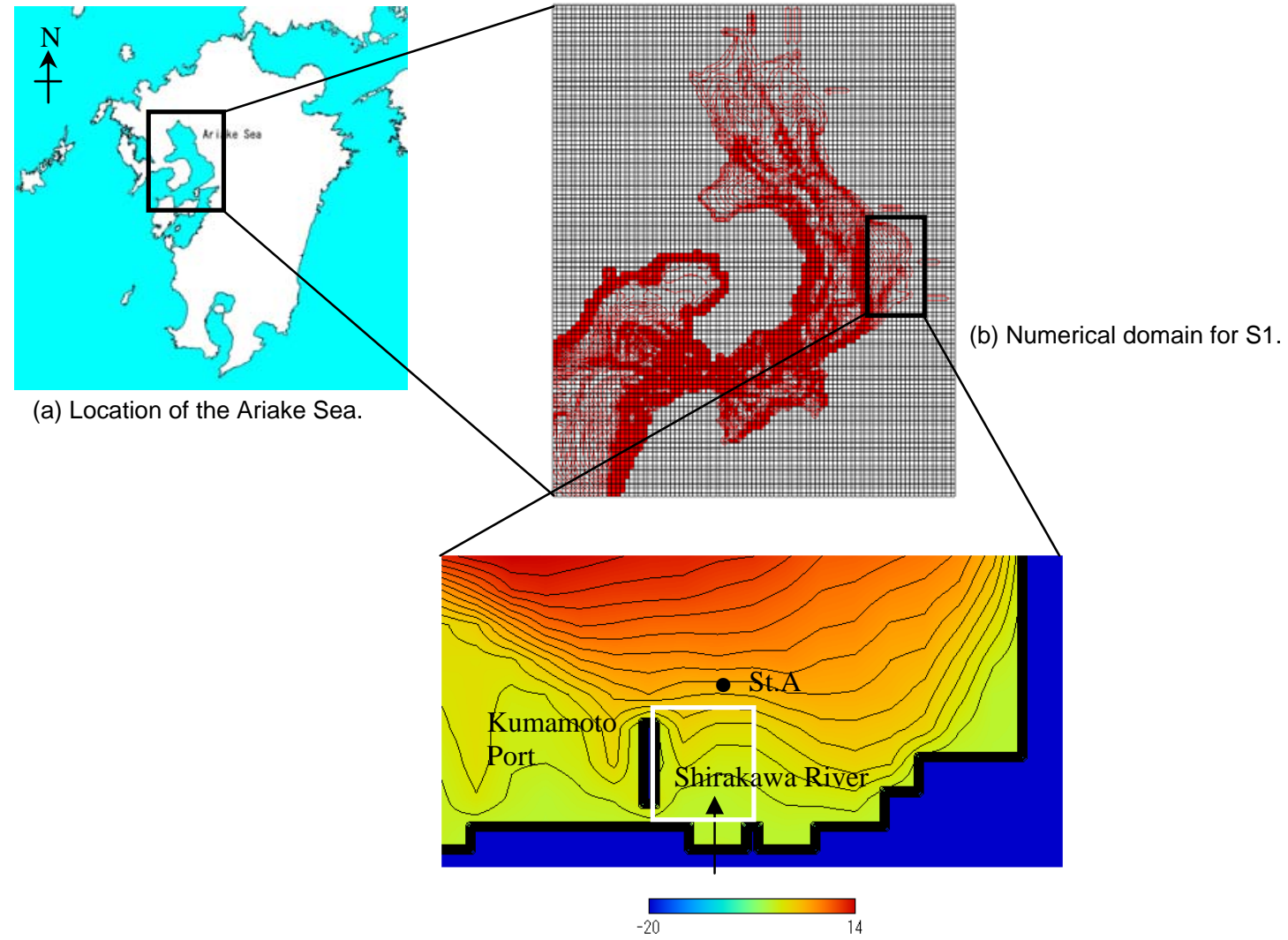

(c) Numerical domain for S2.

Figure 4. Numerical domains. 
Table 1. Numerical conditions (1).

\begin{tabular}{|c|c|c|c|}
\hline & & Run1 & Run2 \\
\hline \multirow[t]{3}{*}{ mesh number } & $\overline{n x}$ & 90 & $\overline{55}$ \\
\hline & ny & 110 & 28 \\
\hline & $\mathrm{nz}$ & 11 & 6 \\
\hline \multirow[t]{2}{*}{ mesh size } & $\mathrm{dx}$ & $900 \mathrm{~m}$ & $300 \mathrm{~m}$ \\
\hline & dy & $900 \mathrm{~m}$ & $300 \mathrm{~m}$ \\
\hline time resolutiol & $\mathrm{dt}$ & $0.5 \mathrm{~s}$ & $0.1 \mathrm{~s}$ \\
\hline
\end{tabular}

Table 2. Numerical conditions (2).

\begin{tabular}{|c|c|c|c|c|}
\hline & currents & sediments & river discharge & mud content \\
\hline $\begin{array}{l}\text { Run } 1 \\
\text { Run } 2\end{array}$ & $\begin{array}{l}\text { tidal+coastal } \\
\text { tidal+coastal }\end{array}$ & $\begin{array}{l}\text { sand+cohesive sediment } \\
\text { sand+cohesive sediment }\end{array}$ & $\begin{array}{l}q=400 \mathrm{~m}^{3} / \mathrm{s} \\
q=20 \mathrm{~m}^{3} / \mathrm{s}\end{array}$ & \\
\hline Run 3 & tidal & sand+cohesive sediment & $q=200 \mathrm{~m}^{3} / \mathrm{s}$ & \\
\hline $\begin{array}{l}\text { Run } 4 \\
\text { Run } 5\end{array}$ & $\begin{array}{l}\text { coastal } \\
\text { coastal }\end{array}$ & $\begin{array}{l}\text { sand }+ \text { cohesive sediment } \\
\text { sand }+ \text { cohesive sediment }\end{array}$ & $\begin{array}{l}q=20 \mathrm{~m}^{3} / \mathrm{s} \\
\mathrm{q}=200 \mathrm{~m}^{3} / \mathrm{s}\end{array}$ & \\
\hline $\begin{array}{l}\text { Run } 6 \\
\text { Run } 7\end{array}$ & $\begin{array}{l}\text { tidal+coastal } \\
\text { tidal+coastal }\end{array}$ & $\begin{array}{l}\text { sand } \\
\text { sand }\end{array}$ & $\begin{array}{l}q=400 \mathrm{~m}^{3} / \mathrm{s} \\
q=20 \mathrm{~m}^{3} / \mathrm{s}\end{array}$ & 㩆 6 \\
\hline $\begin{array}{l}\text { Run } 8 \\
\text { Run } 9\end{array}$ & $\begin{array}{l}\text { tidal+coastal } \\
\text { tidal+coastal }\end{array}$ & $\begin{array}{l}\text { cohesive sediment } \\
\text { cohesive sediment }\end{array}$ & $\begin{array}{l}q=400 \mathrm{~m}^{3} / \mathrm{s} \\
q=20 \mathrm{~m}^{3} / \mathrm{s}\end{array}$ & छ \\
\hline
\end{tabular}

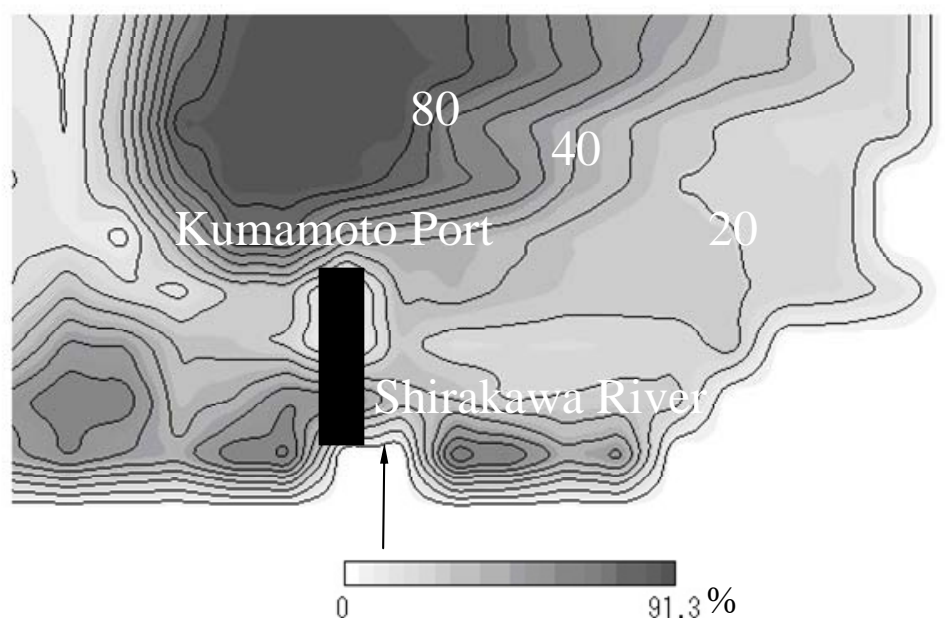

Figure 5. Horizontal distribution of mud content.

\section{Importance of mud content}

Figure.9 (a) and (b) show Run $5+6$ which is the sand only calculation and Run $7+8$ which is the cohesive sediment only calculation. From the distribution of observed mud content, sandy sediments arelocated around the rivermouth of the Shirakawa River, so that figure (a) is more similar with the observed results than figure (b). Figure (b) is quite different from the observed results and it shows the importance of mud content. 


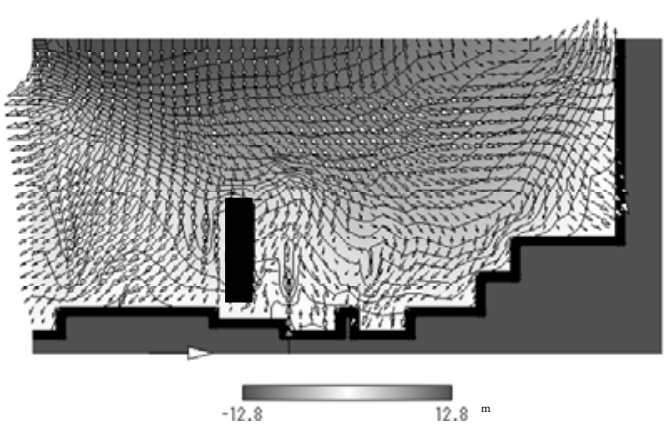

(a) flood tide.

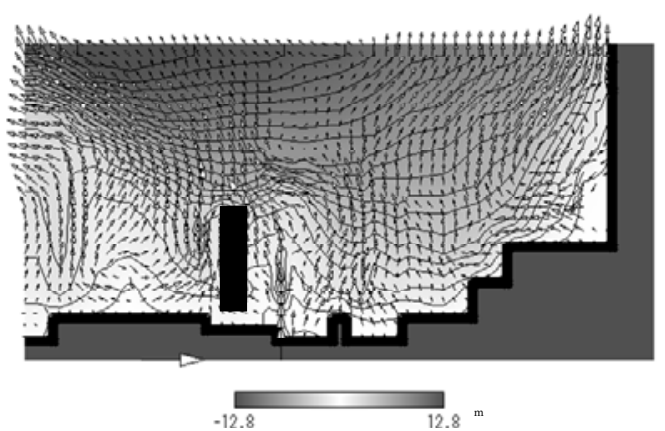

(b) ebb tide.

Figure 6. Horizontal currents.

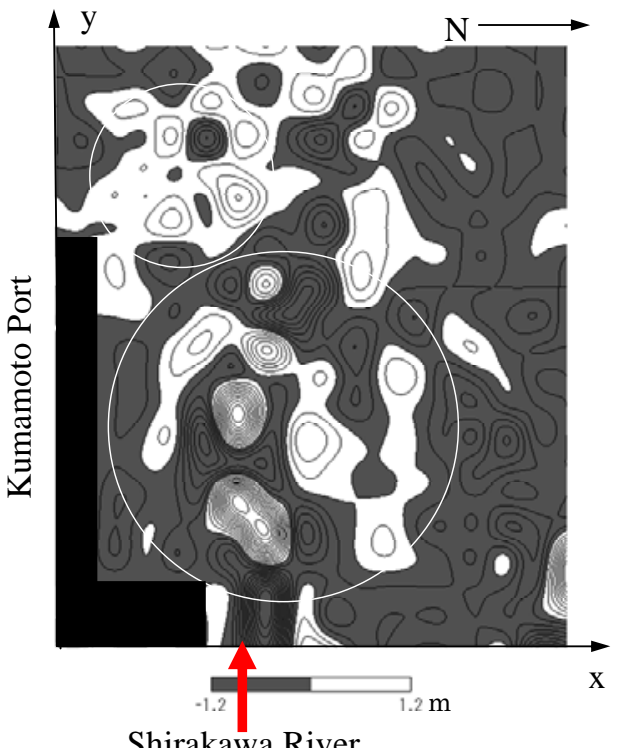

Shirakawa River.
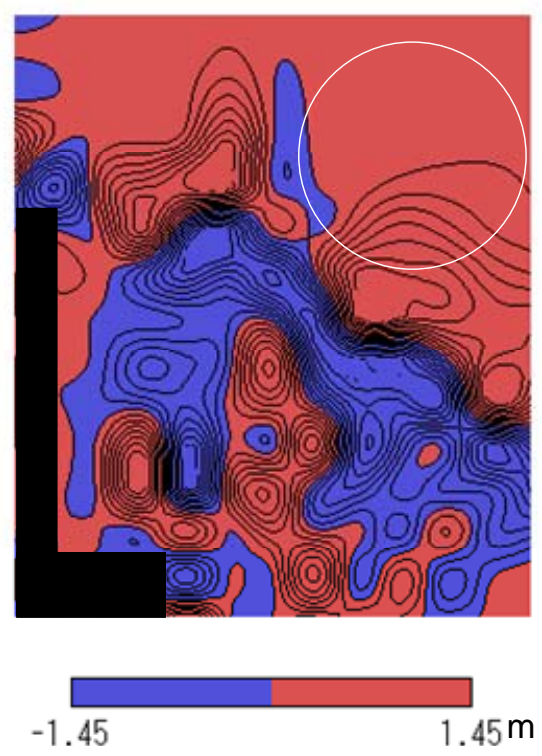

(b) Numerical results.

(a) Observation results

Figure 7. Morphodynamic changes.

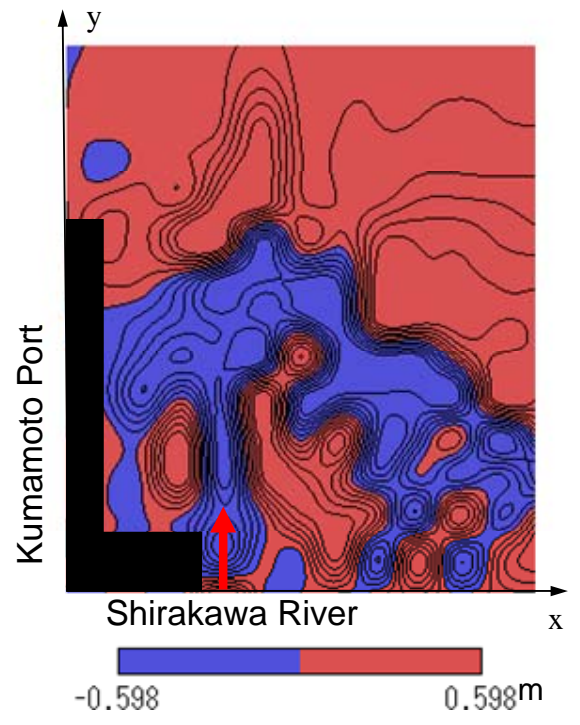

(a) Linear addition of tidal and coastal currents.

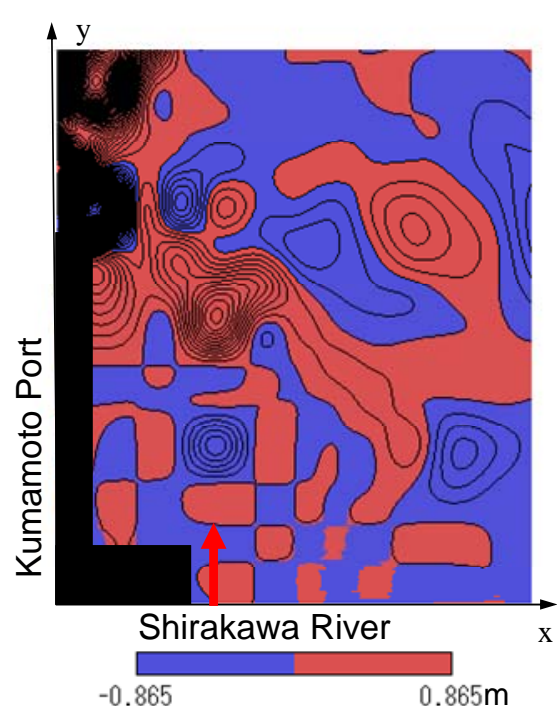

(b) Coastal currents only. Figure 8. Importance of the simultaneous calculation. 


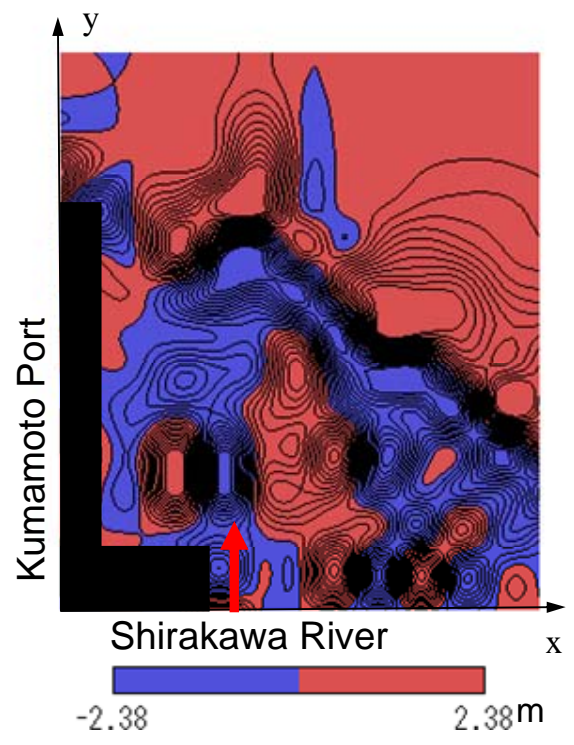

(a) Sand only.

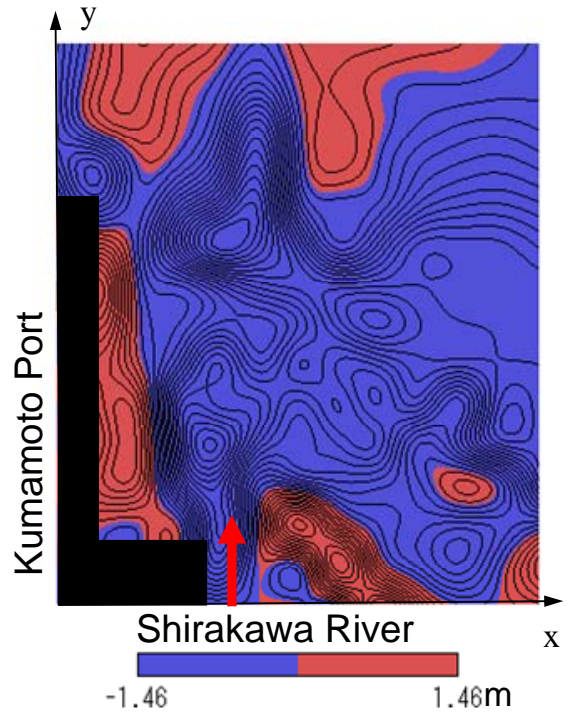

(b) Cohesive sediments only.

Figure 9. Importance of the mud content.

\section{CONCLUSIONS}

Three-dimensional morphodynamic change model of intertidal flat due to tidal and coastal currents considering sand and cohesive sediment transport was established and applied to the Shirakawa intertidal flat in the Ariake Sea in Japan. Comparisons of qualitative features and the order of morphodynamic change between numerical and observation results give us the qualitative validity of the established model. Comparisons also show the importance of simultaneous calculation of tidal and coastal currents and the importance of mud content distribution in order to reproduct precisely the observed morphodynamic change of the intertidal flat. In the future work, the reproductivity of the established model will be confirmed more accurately by using the evaluation function and sediment budgets on the Shirakawa intertidal flat will be estimated as shown in Kuriyama et al. (2004).

\section{REFERENCES}

Kato, S. and T. Yamashita (2004) : Numerical Simulation of Topography Changes Using Coastal Current and Sediment Transport Model in Coasts facing the Japan Sea, Annual Journal of Coastal Engineering, JSCE, Vol.51, pp.511-515 (in Japanese).

Kuriyama, Y. and K. Hashimoto (2004) : Sediment Budget on an Intertidal Flat at the Mouth of the Shirakawa River, Japan, Technical Report of the Port and Airport Research Institute, No.1074 (in Japanese).

Longuet-Higgins M.S. and R.W. Stewart (1962) : Radiation stress and mass transport in gravity waves with application to surf beat, Journal of Fluid Mechanics, 13, pp. 481-504.

Nakagawa, Y. (2003) : Numerical Modeling of Fine Sediment Transport Processes in the Ariake Bay, Report of the Port and Airport Research Institute, Vol.42, No.4, pp.25-42 (in Japanese).

Newberger, P. A. • J. S. Allen (2007a) : Forcing a three-dimensional, hydrostatic, primitive-equation model for application in the surf zone : 1. Formulation, Jour. Geophys. Res., 112, C08018, doi : 10.1029/2006JC003472.

Newberger, P. A. • J. S. Allen (2007b) : Forcing a three-dimensional, hydrostatic, primitive-equation model for application in the surf zone : 2. Application to DUCK94, Jour. Geophys. Res., 112, C08019, doi : 10.1029/2006JC003474.

Uchiyama, Y. 2004. Modeling Wetting and Drying Scheme on an Extended Logarithmic Law for a Three-dimensional Sigma-coordinate Coastal Ocean Model, Report of the Port and Harbour Research Institute, Vol.43, No.4. 
Uchiyama, Y. 2005. Modeling Three-dimensional Cohesive Sediment Transport and Associated Morphological Variation in Estuarine Intertidal Mudflats. Report of the Port and Harbour Research Institute, Vol.44, No.1.

Uzaki, K. and Y. Kuriyama (2007) : Numerical and field study of sediment budgets on an intertidal flat at the mouth of the Shirakawa River, Proc. of the IAHR symposium on River, Coastal and Estuarine Morphodynamics, pp.427-434. 